\title{
Meta-analysis of surgical resection and radiofrequency ablation for early hepatocellular carcinoma
}

\author{
Gang $\mathrm{Xu}^{1 \dagger}$, Fu-zhen $\mathrm{Qi}^{1 \dagger}$, Jian-huai Zhang ${ }^{1}$, Guo-feng Cheng ${ }^{1}$, Yong Cai ${ }^{1}$ and Yi Miao ${ }^{2 *}$
}

\begin{abstract}
Background: There is no definite agreement on the better therapy (radiofrequency ablation (RFA) versus surgical resection (SR)) for early hepatocellular carcinoma (HCC) eligible for surgical treatments. The purpose of this study is to evaluate the evidence using meta-analytical techniques.

Methods: A literature search was undertaken until December 2011 to identify comparative studies evaluating survival rates, recurrence rates, and complications. Pooled odds ratios (OR) and $95 \%$ confidence intervals (95\% Cl) were calculated with either the fixed or random effect model.

Results: Thirteen articles, comprising two randomized controlled trials(RCTs), were included in the review, with a total of 2,535 patients (1,233 treated with SR and 1,302 with RFA). The overall survival rates were significantly higher in patients treated with SR than RFA after1, 3, and 5 years (respectively: OR, 0.60 ( $95 \% \mathrm{Cl}, 0.42$ to 0.86 ); $\mathrm{OR}, 0.49(95 \% \mathrm{Cl}, 0.36$ to 0.65$) ; \mathrm{OR}, 0.60(95 \% \mathrm{Cl}, 0.43$ to 0.84$)$ ). In the $\mathrm{SR}$ group, the 1, 3, and 5 years recurrence rates were significantly lower than the RFA group (respectively: OR, 1.48 ( $95 \% \mathrm{Cl}, 1.05$ to 2.08 ); $\mathrm{OR}, 1.76(95 \% \mathrm{Cl}, 1.49$ to 2.08); $\mathrm{OR}, 1.68$ ( $95 \% \mathrm{Cl}, 1.21$ to 2.34)). However, local recurrence between two groups did not exhibit significant difference. For HCC $\leq 3 \mathrm{~cm}$ in diameter, SR was better than RFA at the 1, 3, and 5 years overall survival rates (respectively: $\mathrm{OR}, 0.34$ (95\% Cl, 0.13 to 0.89); $\mathrm{OR}, 0.56$ (95\% Cl, 0.37 to 0.84); $\mathrm{OR}, 0.44(95 \% \mathrm{Cl}, 0.31$ to 0.62$)$ ). This meta-analysis indicated that the complication of SR was higher than RFA (OR, $6.25(95 \% \mathrm{Cl}, 3.12$ to 12.52); $P=0.000)$.

Conclusion: Although local recurrence between two groups did not exhibit significant difference, SR demonstrated significantly improved survival benefits and lower complications for patients with early HCC, especially for $\mathrm{HCC} \leq 3 \mathrm{~cm}$ in diameter. These findings should be interpreted carefully, owing to the lower level of evidence.
\end{abstract}

Keywords: Hepatocellular carcinoma, meta-analysis, radiofrequency ablation, surgery

\section{Review}

\section{Background}

Hepatocellular carcinoma (HCC) is the seventh most common malignant tumor and the third leading cause of cancer-related deaths worldwide, with an estimated 500,000 deaths per year [1-3]. In past decades, developments of medical devices and interventional techniques have resulted in substantial opportunities for HCC early diagnosis and therapy.

\footnotetext{
* Correspondence: miaoyi@njmu.edu.cn

${ }^{\dagger}$ Equal contributors

2Department of General Surgery, First Affiliated Hospital, Nanjing Medical University, 300 Guangzhou Road, 210029, Nanjing, People's Republic of China Full list of author information is available at the end of the article
}

Current options for the treatment of the early HCC conforming to the Milan criteria (single $\mathrm{HCC} \leq 5 \mathrm{~cm}$ or up to three nodules $\leq 3 \mathrm{~cm}$ ), that is stage I, consist of liver transplantation, surgical resection, transcatheter arterial chemoembolization (TACE), and percutaneous tumor ablation [4-7]. Theoretically, the best treatment is liver transplantation [8-13]. However, the limited availability of suitable living donors, as well as an increased waiting period, has raised the demand for treatment strategies of early HCC, such as SR and local ablation therapies. Comparison of different local ablative methods has shown that RFA is the most effective in terms of both morbidity and the elimination of tumors locally $[14,15]$.

\section{Biomed Central}

(c) 2012 Xu et al.; licensee BioMed Central Ltd. This is an Open Access article distributed under the terms of the Creative Commons Attribution License (http://creativecommons.org/licenses/by/2.0), which permits unrestricted use, distribution, and reproduction in any medium, provided the original work is properly cited. 
Some disputes, however, are reported about RFA and SR. Huang et al. [16], Molinari et al. [17], and Takayama et al. [18] reported that SR had more advantages (survival and recurrence rates) regardless of tumor size (larger or smaller than $3 \mathrm{~cm}$; even smaller than $2 \mathrm{~cm}$ ). However,Chen et al. [19], Hong et al. [20], Vivarelli et al. [21], and Montorsi et al. [22] concluded that RFA was as effective as SR in the treatment of solitary and small HCC. Additionally, Livraghi et al. [23] and Nashikawa et al. [24] considered RFA the first-line treatment for small resectable HCCs.

Whether RFA or SR is the better treatment for early HCC has long been debated. The aim of this review was to examine survival and recurrence rates after RFA and SR for HCC over the past decade.

\section{Materials and methods}

\section{Literature search}

Electronic searches were accomplished of the MEDLINE, Cochrane Controlled Trial Register (CENTRAL) and EMBASE databases until December 2011. The following $\mathrm{MeSH}$ search headings, all in English, were used: surgical resection, hepatic resection or hepatectomy; radiofrequency, radio-frequency or catheter ablation; and liver cancer or hepatocellular carcinoma.

\section{Data extraction and quality assessment}

Two reviewers (Gang Xu and Fuzhen Qi) independently extracted the following parameters from each study: (1) first author and year of the publication; (2) patients characteristics, study design, and following-up; (3) clinical outcomes. Discrepancies between the two reviewers were resolved by discussion. The quality of all selected articles was ranked in accordance with Jadad score.

\section{Inclusion and exclusion criteria}

Inclusion criteria for this study were as follows:(1) compare the initial therapeutic effects of RFA with or without TACE and SR for the treatment of early HCC, despite the etiology of liver disease, differences in viral hepatitis, or cirrhotic status; (2) report at least one of the outcomes mentioned below; (3) clearly document indications for RFA and HR; (4) If two or more studies were reported by the same authors in the same institution, either the study of higher quality or the most recent publication was included in the analysis. The primary endpoints were overall survival rates at 1,3 , and 5 years. The secondary endpoints were disease-free survival rates at 1,3 , and 5 years.

Criteria for exclusion: case reports, letters, abstracts, editorials, expert opinions, studies lacking control groups and reviews without original data were excluded. The following studies were also excluded: (i) those dealing with liver metastases, recurrence after hepatectomy, or unresectable HCC; (ii) those with no clearly reported outcomes of interest; (iii) those treating patients coupling with cholangiocellular carcinomas.

\section{Subgroup analysis}

Subgroup analyses were intended to explore important clinical differences among trials that might be expected to alter the magnitude of treatment effect. A subgroup analysis was performed in this meta-analysis to consider $\mathrm{HCC}$ with single nodules of diameter $\leq 3 \mathrm{~cm}$.

\section{Statistical analysis}

We expressed results for dichotomous outcomes as odds ratio (OR) with 95\% confidence interval (CI) and continuous outcome as weighted mean difference (WMD) or standard mean difference (SMD). Heterogeneity was explored by $\chi^{2}$ and $I^{2}$. If the result of the heterogeneity test was $P>0.1$ and $I^{2}<50 \%$, ORs were pooled using the fixed-effect model(Mantel-Haenszel), otherwise, the random-effect model (DerSimonian and Laird) was used. The significance of the pooled ORs was determined by Z-test. $P<0.05$ was considered significant.

Publication bias was assessed by visual inspection of funnel plots, in which the standard error of $\log (\mathrm{OR})$ of each study was plotted against its $\log (\mathrm{OR})$. An asymmetric plot indicates a possible publication bias. The symmetry of the funnel plot was further evaluated by Begg's and Egger's test. Statistical analysis was undertaken using the Stata software (version11: StataCorp, Texas, USA).

\section{Results}

\section{Study selection and characteristics}

After initial screening, 49 potentially relevant clinical trials of HCC were identified. Of these, 16 trials did not analyze the results of RFA separately from the other therapies, while 14 trials only focused on RFA. These 30 studies were excluded. Six trials were also excluded as no information concerning overall survival after three or five years was provided. A total of 13 studies (2 RCT and 11 NRCTs) [16,19-21,24-32] published between 2000 and 2011 were included.

These studies included a total of 2,535 patients: 1,233 treated with RAF and 1,302 with SR. The mean age ranged from $49.2 \pm 9.9$ to $69.4 \pm 9.1$ years. The male: female ratio in the pooled data was 2.57: 1 . The median or mean tumor size $(\mathrm{cm})$ ranged from 1.8 to 3.8. The median or mean duration of follow-up ranged from 22.7 to 847 months. The quality and characteristics of included studies are shown in Table 1.

\section{Meta-analysis results \\ Overall survival rates}

The meta-analysis showed that there was a significant difference in overall survival between the two groups at one year(12 trials [16,19-21,24-27,29-32], with certain 
Table 1 Quality and characteristics of included studies

\begin{tabular}{|c|c|c|c|c|c|c|c|c|c|}
\hline Reference & Date & Design & $\begin{array}{l}\text { Jadad } \\
\text { score }\end{array}$ & Treatment & $\begin{array}{c}\text { Number of } \\
\text { patients }\end{array}$ & $\operatorname{Sex}(M / F)$ & $\begin{array}{c}\text { Mean age } \\
\text { (years) }\end{array}$ & $\begin{array}{l}\text { Tumor number } \\
\text { (single/multiple) }\end{array}$ & $\begin{array}{l}\text { Mean tumor } \\
\text { size }(\mathrm{cm})\end{array}$ \\
\hline \multirow[t]{2}{*}{ Nishikawa } & 2011 & $\mathrm{NRCT}$ & 1 & SR & 69 & $50 / 19$ & $67.4 \pm 9.7$ & $69 / 0$ & $2.68 \pm 0.49$ \\
\hline & & & & RFA & 162 & $95 / 67$ & $68.4 \pm 8.7$ & $162 / 0$ & $1.99 \pm 0.62$ \\
\hline \multirow[t]{2}{*}{ Tashiro } & 2011 & $\mathrm{NRCT}$ & 1 & $S R$ & 199 & $137 / 62$ & $65.7 \pm 9.0$ & $132 / 67$ & $2.1 \pm 0.63$ \\
\hline & & & & RFA & 87 & $53 / 34$ & $66.3 \pm 8.2$ & $67 / 20$ & $1.8 \pm 0.52$ \\
\hline \multirow[t]{2}{*}{ HUNG } & 2011 & NRCT & 1 & $S R$ & 229 & $184 / 45$ & $60.07 \pm 12.56$ & $181 / 48$ & $2.88 \pm 1.06$ \\
\hline & & & & RFA & 190 & $121 / 69$ & $67.42 \pm 11.45$ & $152 / 38$ & $2.37 \pm 0.92$ \\
\hline \multirow[t]{2}{*}{ Nanashima } & 2010 & $\mathrm{NRCT}$ & 1 & $S R$ & 144 & $112 / 32$ & $63.6 \pm 8.8$ & $128 / 16$ & NA \\
\hline & & & & RFA & 56 & $36 / 20$ & $67.7 \pm 8.5$ & $51 / 5$ & NA \\
\hline \multirow[t]{2}{*}{ Huang } & 2010 & RCT & 4 & $S R$ & 115 & $85 / 30$ & $55.91 \pm 12.68$ & $89 / 26$ & NA \\
\hline & & & & RFA & 115 & $79 / 36$ & $56.57 \pm 14.30$ & $84 / 31$ & NA \\
\hline \multirow[t]{2}{*}{ Ueno } & 2009 & $\mathrm{NRCT}$ & 1 & SR & 123 & $82 / 41$ & 67 (28 to 85$)$ & $110 / 13$ & $2.7 \pm 0.1$ \\
\hline & & & & RFA & 155 & $100 / 55$ & 66 (40 to 79 ) & $101 / 54$ & $2.0 \pm 0.1$ \\
\hline \multirow[t]{2}{*}{ Guglielmi } & 2008 & $\mathrm{NRCT}$ & 1 & SR & 91 & $73 / 18$ & NA & $69 / 22$ & NA \\
\hline & & & & RFA & 109 & $88 / 21$ & NA & $65 / 44$ & NA \\
\hline \multirow[t]{2}{*}{ Hiraoka } & 2008 & $\mathrm{NRCT}$ & 1 & $S R$ & 59 & $44 / 15$ & $62.4 \pm 10.6$ & NA & $22.7 \pm 5.5$ \\
\hline & & & & RFA & 105 & $76 / 29$ & $69.4 \pm 9.1$ & NA & $19.8 \pm 5.2$ \\
\hline \multirow[t]{2}{*}{ Abu-Hilal } & 2008 & $\mathrm{NRCT}$ & 3 & $S R$ & 34 & $26 / 8$ & 67 & NA & 3.8 (1.3 to 5$)$ \\
\hline & & & & RFA & 34 & $27 / 7$ & 65 & NA & 3 (2 to 5) \\
\hline \multirow[t]{2}{*}{ Takahashi } & 2007 & $\mathrm{NRCT}$ & 1 & $S R$ & 53 & $39 / 14$ & 66 (41 to 80 ) & $41 / 12$ & 2.5 (1 to 5$)$ \\
\hline & & & & RFA & 171 & $120 / 51$ & 69 (44 to 84$)$ & $124 / 47$ & 2.1 (0.7 to 4.8 ) \\
\hline \multirow[t]{2}{*}{ Chen } & 2006 & $\mathrm{RCT}$ & 4 & SR & 90 & $75 / 15$ & $49.4 \pm 10.9$ & NA & NA \\
\hline & & & & RFA & 71 & $56 / 15$ & $51.9 \pm 11.2$ & NA & NA \\
\hline \multirow[t]{2}{*}{ Hong } & 2005 & $\mathrm{NRCT}$ & 1 & $S R$ & 93 & $69 / 24$ & $49.2 \pm 9.9$ & NA & $2.5 \pm 0.8$ \\
\hline & & & & RFA & 55 & $41 / 14$ & $59.1 \pm 9.6$ & NA & $2.4 \pm 0.6$ \\
\hline \multirow[t]{2}{*}{ Vivarell } & 2004 & $\mathrm{NRCT}$ & 2 & $S R$ & 79 & $57 / 22$ & $65.2 \pm 8.2$ & $66 / 13$ & NA \\
\hline & & & & RFA & 79 & $67 / 12$ & $67.8 \pm 8.7$ & $46 / 33$ & NA \\
\hline
\end{tabular}

NA: Not available; NRCT: non-randomized controlled trial; RCT: randomized controlled trial; RFA: radiofrequency ablation; SR: surgical resection.

heterogeneity), three years(13 trials [16,19-21,24-32], without heterogeneity) and five years(10 trials [16,24-32], without heterogeneity) and that the SR group was favored (see Table 2).

\section{Recurrence rates}

Our results, as shown in Table 2, indicated that recurrence rates at one year(13 trials [16,19-21,24-32], without heterogeneity), three years(13 trials [16,19-21,24-32], without heterogeneity) and five years(10 trials [16,24-32], without heterogeneity) were significantly higher in the RFA group than in the SR group. However, no differences were found between the two groups (4 trials $[16,20,24,30])$ with respect to the local intrahepatic recurrence (see Table 2).

\section{Complications}

The meta-analysis (7 trials [16,19,24,25,27,30,32] reported these data) showed that there was significant difference between the two groups (OR, 6.25 [95\%CI, 3.12 to 12.52]; $P=0.000$ ), without heterogeneity (see Table 2 ). The RFA group was favored.

\section{Subgroup analysis in HCCs $\leq 3 \mathrm{~cm}$}

The meta-analysis (6 trials [16,21,24,27-29] reported these data) showed that the difference was significant and favorable to the SR group at 1,3 and 5 years (respectively, OR, 0.34 [95\%CI, 0.13 to 0.89]; OR, 0.56 [95\% CI, 0.37 to 0.84$]$; OR, 0.44 [95\%CI, 0.31 to 0.62 ] (see Figures 1, 2, 3).

\section{Sensitivity analysis}

To compare the difference and evaluate the sensitivity of the meta-analysis, we employed one-way sensitivity analysis to evaluate the stability of the meta-analysis. The statistical significance of the results was not altered when any single study was omitted (data not shown). 
Table 2 Main results of the pooled data in the meta-analysis

\begin{tabular}{|c|c|c|c|c|c|c|c|}
\hline Variables & $\begin{array}{l}\text { Number of references } \\
\text { with data }\end{array}$ & OR $(95 \% \mathrm{Cl})$ & $\begin{array}{l}\text { Q test } \\
\text { (Pvalue) }\end{array}$ & $I^{2}(\%)$ & $\begin{array}{l}Z \text { test } \\
\text { (Pvalue) }\end{array}$ & $\begin{array}{l}\text { Begg's } \\
\text { test (Pvalue) }\end{array}$ & $\begin{array}{l}\text { Egger's } \\
\text { test (Pvalue) }\end{array}$ \\
\hline \multicolumn{8}{|c|}{ Overall survival rates } \\
\hline 1 year & $12[16,19-21,24-27,29-32]$ & $0.60(0.42,0.86)$ & 0.301 & 14.6 & 0.005 & 0.54 & 0.40 \\
\hline 3 years & $13[16,19-21,24-32]$ & $0.49(0.36,0.65)$ & 0.036 & 45.8 & 0.000 & 0.2 & 0.15 \\
\hline 5 years & $10[16,24-32]$ & $0.60(0.43,0.84)$ & 0.003 & 63.7 & 0.003 & 0.37 & 0.57 \\
\hline \multicolumn{8}{|l|}{ Recurrence rates } \\
\hline 1 year & 13 [16,19-21,24-32] & $1.48(1.05,2.08)$ & 0.001 & 63.4 & 0.025 & 1.00 & 0.61 \\
\hline 3 years & $13[16,19-21,24-32]$ & $1.76(1.49,2.08)$ & 0.000 & 69.9 & 0.000 & 0.20 & 0.15 \\
\hline 5 years & $10[16,24-32]$ & $1.68(1.21,2.34)$ & 0.02 & 54.4 & 0.002 & 0.86 & 0.92 \\
\hline Local recurrence & $4[16,20,24,30]$ & $0.34(0.09,1.28)$ & 0.02 & 68.9 & 0.112 & NA & NA \\
\hline Complications & $7[16,19,24,25,27,30,32]$ & $6.25(3.12,12.52)$ & 0.042 & 54 & 0.000 & 1 & 0.982 \\
\hline
\end{tabular}

$\mathrm{NA}$, not available.Q test and $I^{2}$ were used to evaluate the heterogeneity of the studies; $Z$ test was used to value the combined effect; Begg's and Egger's tests were used to assess the publication bias.

Therefore, results of the sensitivity analysis suggest that the data in this meta-analysis are relatively robust.

\section{Publication bias}

Funnel plots (Figure 4) were created to assess possible publication biases. In addition, Begg's and Egger's tests were used to evaluate the symmetry of the plots. As shown in Table 2, the data suggest that the funnel plots were symmetrical, and that publication biases might not have an evident influence on the results of the meta-analyses.

\section{Discussion}

There is some dispute whether survival benefits of RFA exist for patients with early HCC compared with SR. This meta-analysis demonstrated that RFA with or without TACE was inferior to SR in terms of overall survival rates and recurrence rates at one, three, and five years, contrary to the opinion of Livraghi [23]. This may be partly explained by advances in surgical and radiological techniques and perioperative care, and by more cautious patient selection [33,34]. This finding may also be adversely impacted by the delay of surveillance in effective treatment using RFA [35,36].

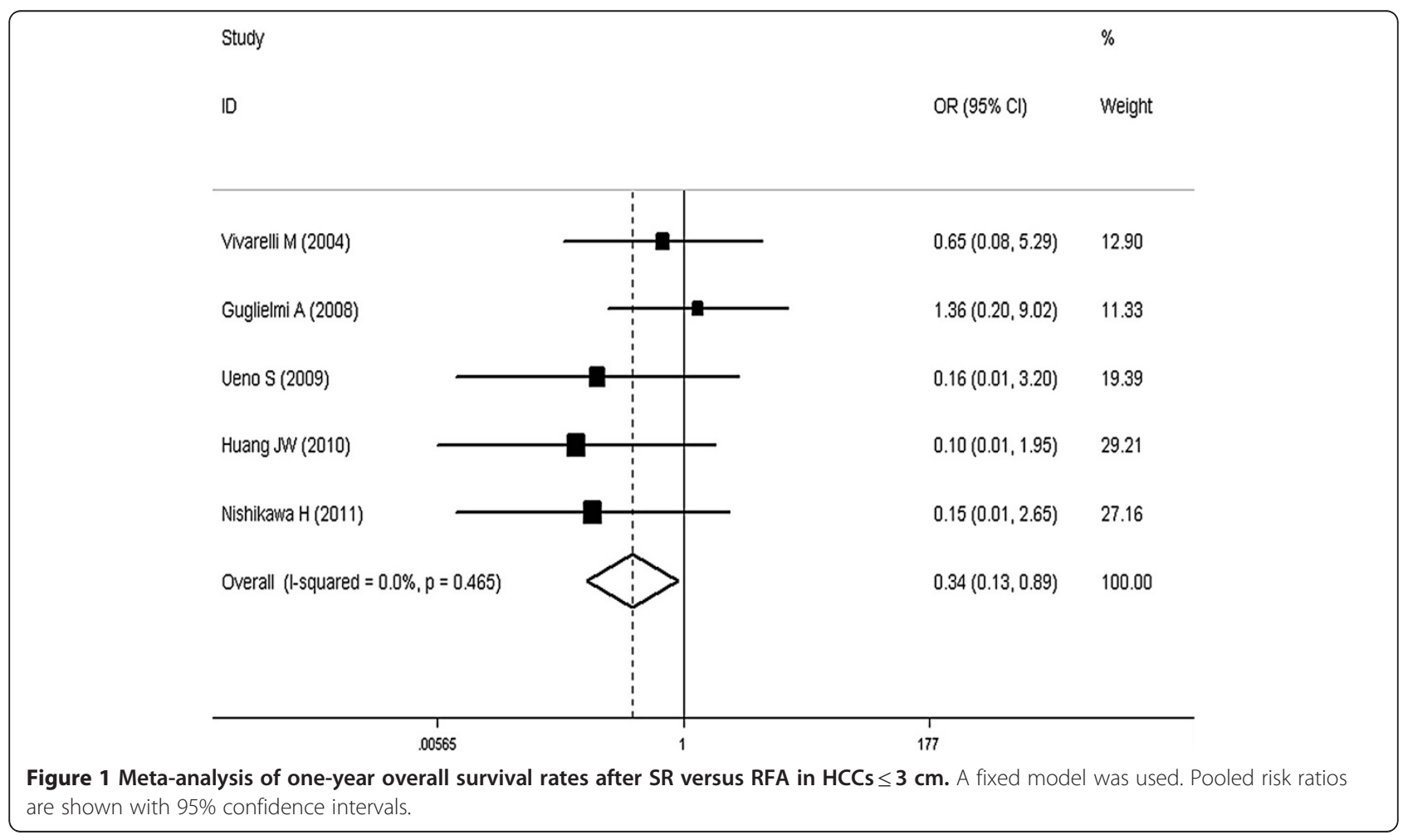




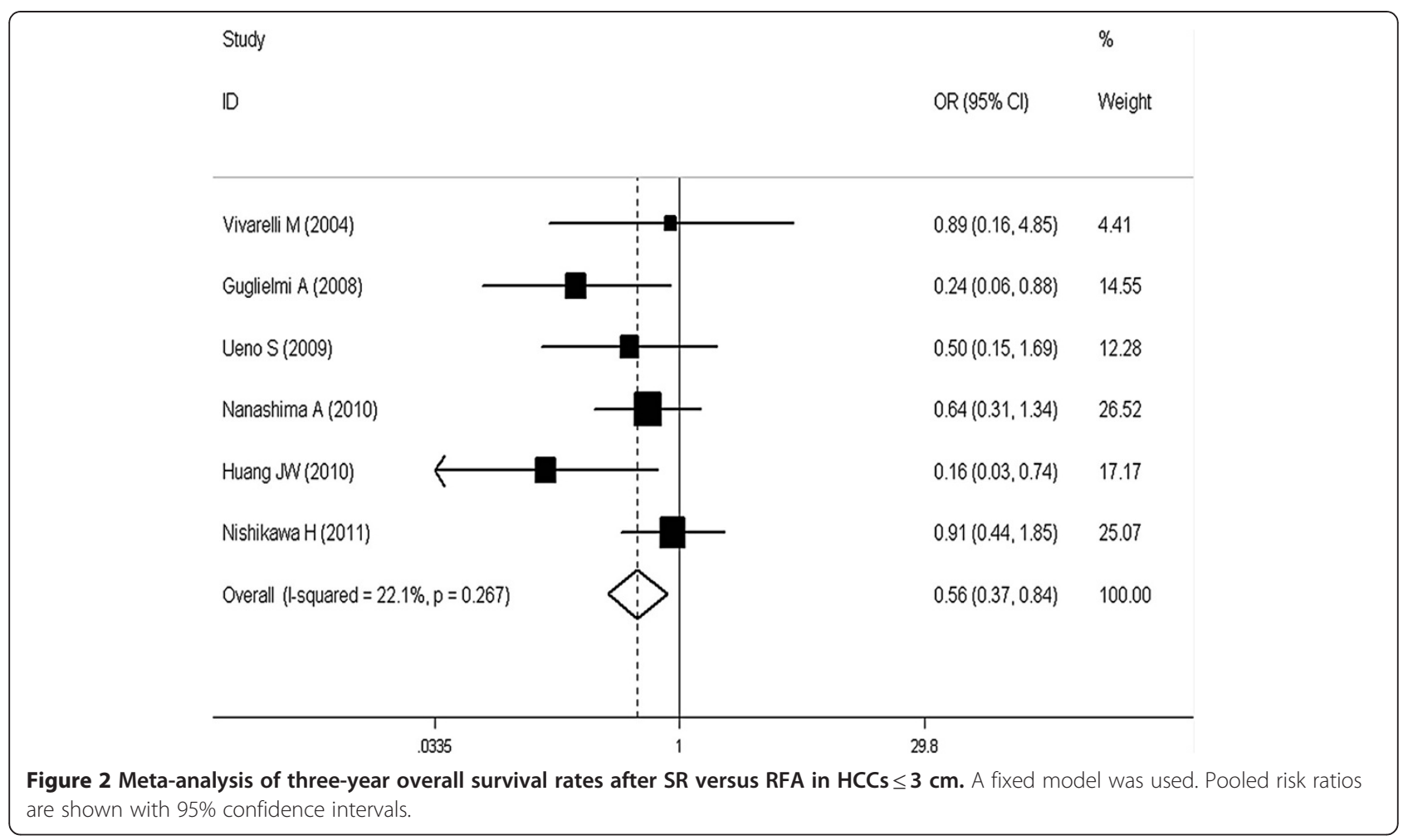

A high rate of recurrence after treatment is the main factor affecting overall survival and late death of patients with HCC [37]. Reportedly, the risk factors for tumor recurrence after treatment include tumor location, tumor size, multinodular tumors, and an insufficient safety margin [38-40]. Additionally, recurrences arise because of pre-existing microscopic tumor foci that were undetected by imaging modalities, or because malignant

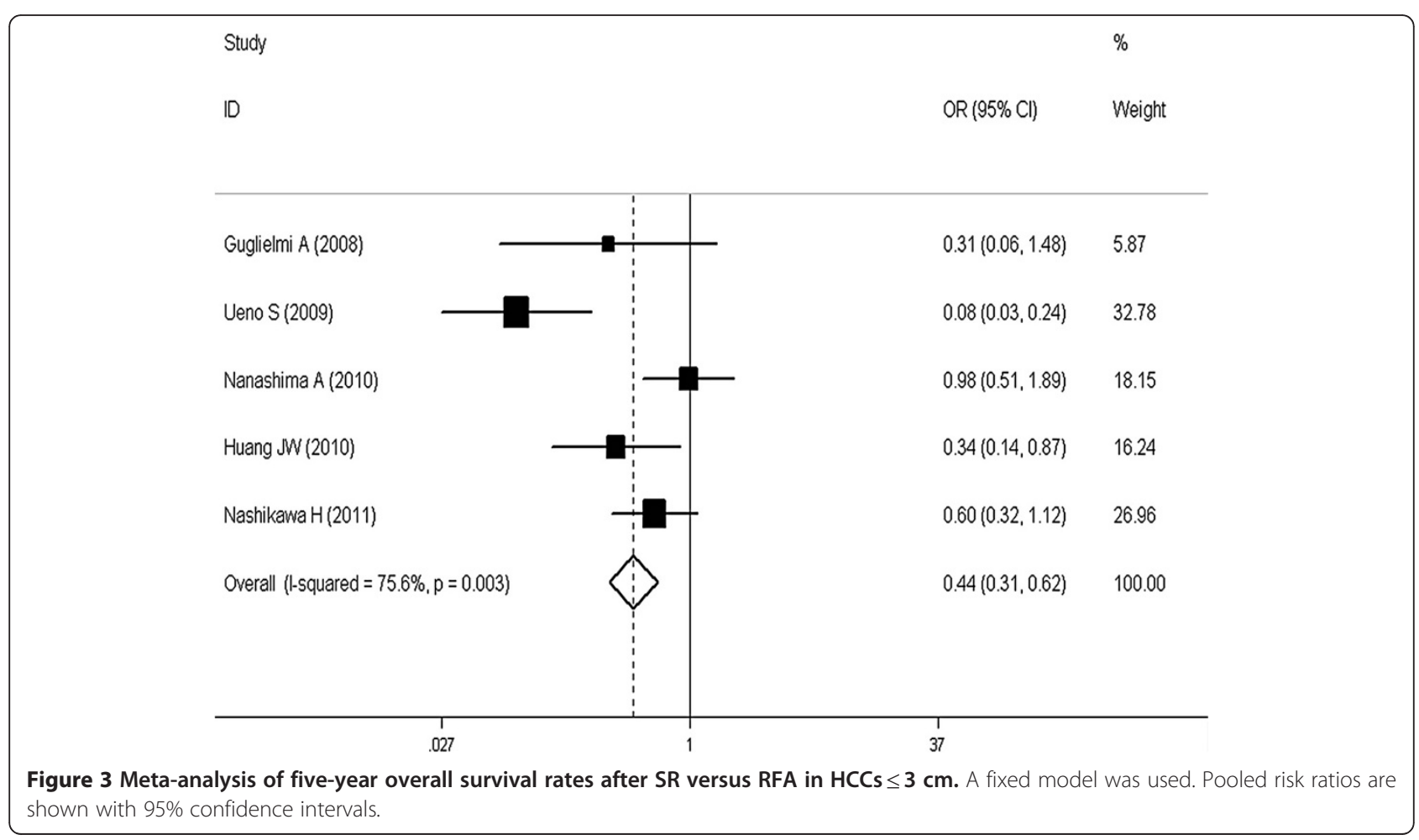




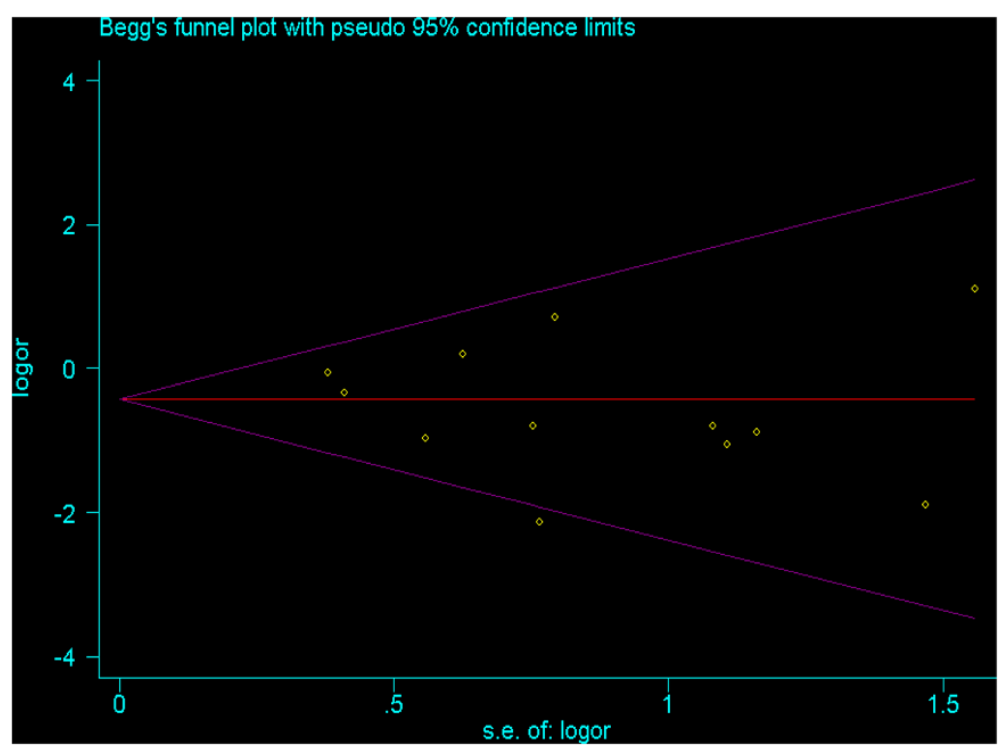

Figure 4 Funnel plots on one-year overall survival rates following RFA and SR for the treatment of early HCC.

cells disseminated during operation $[41,42]$. In this study, recurrence was found to be more frequent after RFA than SR. This may be a result of the safety margin of RFA being narrower than that of SR, as SR usually excises the entire Couinaud segments containing tumors and possible venous tumor thrombus. In addition, high rates of recurrence after RFA may result from insufficient ablation of the primary tumor or the presence of tumor venous invasion in the adjacent liver. As for local intrahepatic recurrence rates, the two groups had no difference. This may be due to the development of techniques of RFA and an accurate evaluation of treatment response via a sufficient safety margin (at least $0.5 \mathrm{~cm}$ ).

This meta-analysis suggested that the incidence of complications after RFA for HCC was lower than those after the SR group as a result of the microinvasive characterization of RFA. Radiofrequency ablation is a minimally invasive, target-selective technique, which has been applied in clinical studies in the 1990s [43]: it can induce thermal lesions less than 2.5 to $3.5 \mathrm{~cm}$ in diameter, using single expandable-tip electrodes, which are handled percutaneously and guided by imaging modalities [44]. This procedure could be performed under conscious sedation and the hospital stay is then shortened.

The subgroup analysis showed marked differences in the overall survival rates between RFA and SR for $\mathrm{HCC} \leq 3 \mathrm{~cm}$ after one, three, and five years. Considering the fact that patients with single $\mathrm{HCC} \leq 3 \mathrm{~cm}$ in diameter were at early stage without micro metastases and vascular invasion, SR can achieve better clinic outcomes. However, a lack of sufficient data on RCTs and an unequal constitution of patients may also affect these findings.
The majority of the data in the present study came from non-RCTs, so the overall level of clinical evidence might be low. However, a firm conclusion about bias is difficult to reach as the asymmetry of the funnel plot is minimal. Therefore our pooled OR might be an overestimate of the true effect.

\section{Conclusion}

In conclusion, SR demonstrated significantly improved survival benefits for patients with early HCC, especially for $\mathrm{HCC} \leq 3 \mathrm{~cm}$ in diameter, although local recurrence between two groups did not exhibit significant difference. However, the findings need to be carefully interpreted, owing to the lower level of evidence. Further RCTs are warranted to clarify the exact value of SR and RFA for early $\mathrm{HCC}$, especially for single nodules $\leq 3 \mathrm{~cm}$ in diameter.

\section{Abbreviations}

$\mathrm{Cl}$ : confidence interval; HCC: hepatocellular carcinoma; OR: odds ratio; $\mathrm{RCT}$ : randomized controlled trial; RFA: radiofrequency ablation; SMD: standard mean difference; SR: surgical resection; TACE: transcatheter arterial chemoembolization; WMD: weighted mean difference.

\section{Competing interests}

The authors declare that they have no competing interests.

\section{Authors' contributions}

XG, QFZ, and MY designed the studyand wrote the manuscript.XG, QFZ, ZJH, CGF, and $C Y$ performed data acquisition.MY performed quality control of data.XG, QFZ, and MY performed statistical analysis and interpretation. All authors read and approved the final manuscript. XG and QFZ contributed equally to this work.

\section{Author details}

'Department of General Surgery, Huai'an First People's Hospital, Nanjing Medical University, 6 Beijing Road West, 223300, Huai'an, Jiangsu Province, 
People's Republic of China. ${ }^{2}$ Department of General Surgery, First Affiliated Hospital, Nanjing Medical University, 300 Guangzhou Road, 210029, Nanjing, People's Republic of China.

Received: 9 April 2012 Accepted: 15 July 2012

Published: 16 August 2012

\section{References}

1. Ferlay J, Shin HR, Bray F, Forman D, Mathers C, Parkin DM: Estimates of worldwide burden of cancer in 2008: GLOBOCAN 2008. Int J Cancer 2010, 127:2893-2917.

2. Jemal A, Bray F, Center MM, Ferlay J, Ward E, Forman D: Global cancer statistics. CA Cancer J Clin 2011, 61:69-90.

3. Yang JD, Roberts LR: Hepatocellular carcinoma: aglobal view. Nat Rev GastroenterolHepatol 2010, 7:448-458.

4. Benson AB 3rd, Abrams TA, Ben-Josef E, Bloomston PM, Botha JF, Clary BM, Covey A, Curley SA, D'Angelica MI, Davila R, Ensminger WD, Gibbs JF, Laheru D, Malafa MP, Marrero J, Meranz SG, Mulvihill SJ, Park JO, Posey JA, Sachdev J, Salem R, Sigurdson ER, Sofocleous C, Vauthey JN, Venook AP, Goff LW, Yen Y, Zhu AX: NCCN clinical practice guidelines in oncology: hepatobiliarycancers. JNat/ComprCancNetw 2009, 7:350-391.

5. Llovet JM, Burroughs A, Bruix J: Hepatocellular carcinoma. Lancet 2003, 362:1907-1917.

6. Llovet JM, Bruix J: Novel advancements in the management of hepatocellular carcinoma in 2008. J Hepato/ 2008, 48(Suppl 1):S20-S37.

7. Zhang YY, Xia HH: Novel therapeutic approaches for hepatocellular carcinoma: fact and fiction. World J of Gastroenterol 2008, 14:1641-1642.

8. Merchant N, David CS, Cunningham SC: Early hepatocellular carcinoma: transplantation versus resection: the case for liver resection. Int I Hepatol 2011, 2011:142085.

9. Lee KK, Kim DG, Moon IS, Lee MD, Park JH: Liver transplantation versus liver resection for the treatment of hepatocellular carcinoma. J Surg Oncol 2010, 101:47-53.

10. Sotiropoulos GC, Druhe N, Sgourakis G, Molmenti EP, Beckebaum S, Baba HA, Antoch G, Hilgard P, Radtke A, Saner FH, Nadalin S, Paul A, Malagó M, Broelsch CE, Lang H: Liver transplantation, liver resection, and transarterial chemoembolization for hepatocellular carcinoma in cirrhosis: which is the best oncological approach? Dig Dis Sci 2009, 54:2264-2273.

11. Hasegawa K, Kokudo N, Makuuchi M: Surgical management of hepatocellular carcinoma. Liver resection and liver transplantation. Saudi Med J 2007, 28:1171-1179.

12. Zhou J, Wang Z, Qiu SJ, Huang XW, Sun J, Gu W, Fan J: Surgical treatment for early hepatocellular carcinoma: comparison of resection and liver transplantation. J Cancer Res ClinOncol 2010, 136:1453-1460.

13. Bruix J, Sherman M: Management of hepatocellular carcinoma: an update. Hepatology 2011, 53:1020-1022.

14. Peng ZW, Zhang YJ, Chen MS, Lin XJ, Liang HH, Shi M: Radiofrequency ablation as first-line treatment for small solitary hepatocellular carcinoma: long-term results. Eur J SurgOncol 2010, 36:1054-1060.

15. Tiong L, Maddern GJ: Systematic review and meta-analysis of survival and disease recurrence after radiofrequency ablation for hepatocellular carcinoma. Br J Surg 2011, 98:1210-1224.

16. Huang J, Yan L, Cheng Z, Wu H, Du L, Wang J, Xu Y, Zeng Y: A randomized trial comparing radiofrequency ablation and surgical resection for $\mathrm{HCC}$ conforming to the Milan criteria. AnnSurg 2010, 252:903-912.

17. Molinari $\mathrm{M}$, Helton S: Hepatic resection versus radiofrequency ablation for hepatocellular carcinoma in cirrhotic individuals not candidates for liver transplantation: a Markov model decision analysis. Am J Surg 2009, 198:396-406.

18. Takayama T, Makuuchi M, Hasegawa K: Single HCC smaller than $2 \mathrm{~cm}$ : surgery or ablation?: surgeon's perspective. JHepatobiliaryPancreatSci 2010, 17:422-424

19. Chen MS, Li JQ, Zheng Y, Guo RP, Liang HH, Zhang YQ, Lin XJ, Lau WY: A prospective randomized trial comparing percutaneous local ablative therapy and partial hepatectomy for small hepatocellular carcinoma. AnnSurg 2006, 243:321-328.

20. Hong SN, Lee SY, Choi MS, Lee JH, Koh KC, Paik SW, Yoo BC, Rhee JC, Choi D, Lim HK, Lee KW, Joh JW: Comparing the outcomes of radiofrequency ablation and surgery in patients with a single small hepatocellular carcinoma and well-preserved hepatic function. JClinGastroenterol 2005, 39:247-252.

21. Vivarelli M, Guglielmi A, Ruzzenente A, Cucchetti A, Bellusci R, Cordiano C, Cavallari A: Surgical resection versus percutaneous radiofrequency ablation in the treatment of hepatocellular carcinoma on cirrhotic liver. Annsurg 2004, 240:102-107.

22. Montorsi M, Santambrogio R, Bianchi P, Donadon M, Moroni E, Spinelli A, Costa M: Survival and recurrences after hepatic resection or radiofrequency for hepatocellular carcinoma in cirrhotic patients: a multivariate analysis. JGastrointestSurg 2005, 9:62-67.

23. Livraghi T, Meloni F, Di Stasi M, Rolle E, Solbiati L, Tinelli C, Rossi S: Sustained complete response and complications rates after radiofrequency ablation of very early hepatocellular carcinoma in cirrhosis: Is resection still the treatment of choice? Hepatology 2008, 47:82-89.

24. Nishikawa H, Inuzuka T, Takeda H, Nakajima J, Matsuda F, Sakamoto A, Henmi S, Hatamaru K, Ishikawa T, Saito S, Nasu A, Kita R, Kimuar T, Arimoto A, Osaki Y: Comparison of percutaneous radiofrequency thermal ablation and surgical resection for small hepatocellular carcinoma. BMCgastroenterol 2011, 11:143.

25. Hiraoka A, Horiike N, Yamashita Y, Koizumi Y, Doi K, Yamamoto Y, Hasebe A, Ichikawa S, Yano M, Miyamoto Y, Ninomiya T, Otomi Y, Kokame M, Iwamura T, Ishimaru Y, Sogabe I, Kashihara K, Nishiura S, Ootani H, Takamura K, Kawasaki H: Efficacy of radiofrequency ablation therapy compared to surgical resection in 164 patients in Japan with single hepatocellular carcinoma smaller than $3 \mathrm{~cm}$, along with report of complications. Hepato-gastroenterology 2008, 55:2171-2174.

26. Takahashi S, Kudo M, Chung H, Inoue T, Nagashima M, Kitai S, Tatsumi C, Minami Y, Ueshima K, Fukunaga T, Haji S: Outcomes of nontransplant potentially curative therapy for early-stage hepatocellular carcinoma in Child-Pugh stage A cirrhosis is comparable with liver transplantation. Dig Dis 2007, 25:303-309.

27. Guglielmi A, Ruzzenente A, Valdegamberi A, Pachera S, Campagnaro T, D'Onofrio M, Martone E, Nicoli P, lacono C: Radiofrequency ablation versus surgical resection for the treatment of hepatocellular carcinoma in cirrhosis. JGastrointestSrug 2008, 12:192-198.

28. Nanashima A, Tobinaga S, Masuda J, Miyaaki H, Taura N, Takeshita H, Hidaka S, Sawai T, Nakao K, Nagayasu T: Selecting treatment for hepatocellular carcinoma based on the results of hepatic resection and local ablation therapy. JSurgOncol 2010, 101:481-485.

29. Ueno S, Sakoda M, Kubo F, Hiwatashi K, Tateno T, Baba Y, Hasegawa S, Tsubouchi H: Surgical resection versus radiofrequency ablation for small hepatocellular carcinomas within the Milan criteria. JHepatobiliary Pancreatic Surg 2009, 16:359-366.

30. Abu-Hilal M, Primrose JN, Casaril A, McPhail MJ, Pearce NW, Nicoli N: Surgical resection versus radiofrequency ablation in the treatment of small unifocal hepatocellular carcinoma. JGastrointestSurg 2008, 12:1521-1526.

31. Hung HH, Chiou YY, Hsia CY, Su CW, Chou YH, Chiang JH, Kao WY, Huo TI, Huang YH, Su YH, Lin HC, Lee SD, Wu JC: Survival rates are comparable after radiofrequency ablation or surgery in patients with small hepatocellular carcinomas. ClinGastroenterolHepatol 2011, 9:79-86.

32. Tashiro H, Aikata H, Waki K, Amano H, Oshita A, Kobayashi T, Tanimoto Y, Kuroda S, Tazawa H, Chayama K: Treatment strategy for early hepatocellular carcinomas: comparison of radiofrequency ablation with or without transcatheter arterial chemoembolization and surgical resection. JSurgOncol 2011, 104:3-9.

33. Kudo M: Radiofrequency ablation for hepatocellular carcinoma: updated review in 2010. Oncology 2010, 78(Suppl 1):113-124.

34. Rahbari NN, Mehrabi A, Mollberg NM, Muller SA, Koch M, Buchler MW, Weitz J: Hepatocellular carcinoma: current management and perspectives for the future. AnnSurg 2011, 253:453-469.

35. Chen WT, Fernandes ML, Lin CC, Lin SM: Delay in treatment of early-stage hepatocellular carcinoma using radiofrequency ablation may impact survival of cirrhotic patients in a surveillance program. JSurgOncol 2011, 103:133-139.

36. Wong GL, Wong WW, Tan GM, Ip KI, Lai WK, Li YW, Mak MS, Lai PB, Sung JJ, Chan $\mathrm{HL}$ : Surveillance programme for hepatocellular carcinoma improves the survival of patients with chronic viral hepatitis. Liverlnt 2008, 28:79-87.

37. Blum HE, Spangenberg HC: Hepatocellular carcinoma: an update. Arch Iran Med 2007, 10:361-371. 
38. Liu L, Miao R, Yang H, Lu X, Zhao Y, Mao Y, Zhong S, Huang J, Sang X, Zhao H: Prognostic factors after liver resection for hepatocellular carcinoma: a single-center experience from China. Am J Surg 2012, 203:741-750.

39. Ko CJ, Chien SY, Chou CT, Chen LS, Chen ML, Chen YL: Factors affecting prognosis of small hepatocellular carcinoma in Taiwanese patients following hepatic resection. Can J Gastroenterol 2011, 25:485-491.

40. Grat M, Holowko W, Grzegorczyk K, Skalski M, Krawczyk M: Long-term results of liver resection in the treatment of patients with hepatocellular carcinoma. PolPrzeg/Chir 2011, 83:319-324.

41. Ohashi M, Wakai T, Korita PV, Ajioka Y, Shirai Y, Hatakeyama K: Histological evaluation of intracapsular venous invasion for discrimination between portal and hepatic venous invasion in hepatocellular carcinoma. JGastroenterolHepatol 2010, 25:143-149.

42. Park YN: Pathology of hepatocellular carcinoma: recent update. Korean $J$ Gastroenterol 2005, 45:227-233.

43. Bangard C: Radiofrequency of the liver - an update. RoFo 2011, 183:704-713.

44. Rossi S, Ravetta V, Rosa L, Ghittoni G, Viera FT, Garbagnati F, Silini EM, Dionigi P, Calliada F, Quaretti P, Tinelli C: Repeated radiofrequency ablation for management of patients with cirrhosis with small hepatocellular carcinomas: a long-term cohort study. Hepatology 2011, 53:136-147.

doi:10.1186/1477-7819-10-163

Cite this article as: Xu et al:: Meta-analysis of surgical resection and radiofrequency ablation for early hepatocellular carcinoma. World Journal of Surgical Oncology 2012 10:163.

\section{Submit your next manuscript to BioMed Central and take full advantage of:}

- Convenient online submission

- Thorough peer review

- No space constraints or color figure charges

- Immediate publication on acceptance

- Inclusion in PubMed, CAS, Scopus and Google Scholar

- Research which is freely available for redistribution 